\title{
Bacteremia-Induced Suppression of Alveolar Surfactant Production ${ }^{1,2}$
}

\author{
K. T. Oldham, M.D., K. S. Guice, M.D.,* P. S. Stetson, M.D., Ph.D.,† and R. R. Wolfe, Ph.D. \\ Sections of Pediatric Surgery and *General Surgery, Department of Surgery and the †Department of Pharmacology, Upjohn Center \\ for Clinical Pharmacology, University of Michigan Medical School, Ann Arbor, Michigan 48109-0245; and the \\ $\ddagger$ Shriner’s Burns Institute, University of Texas Medical Branch, Galveston, Texas 77550
}

Submitted for publication November 16, 1988

Sepsis is characterized by Adult Respiratory Distress Syndrome (ARDS)-like pulmonary dysfunction largely attributed to alveolar capillary endothelial cell injury which causes increased microvascular permeability and interstitial edema formation. In addition, quantitative and qualitative abnormalities of the pulmonary surfactant system may be important features of some clinical and experimental lung injuries. This study was designed to investigate the relationship of bacteremia and endotoxemia to pulmonary surfactant production in vivo. A technique for estimation of pulmonary surfactant phospholipid synthesis measuring incorporation of a stable isotope precursor $\left(\left[2-{ }^{13} \mathrm{C}\right]\right.$ acetate $)$ into dipalmitoylphosphatidylcholine (DPPC) in alveolar lavage fluid was developed. Male $350 \mathrm{~g}$ Sprague-Dawley rats had placement of central venous catheters. After overnight recovery, sublethal bacteremia (Escherichia coli, $1 \times 10^{8}$ organisms, iv) and sublethal endotoxemia (Difco; $10 \mathrm{mg} / \mathrm{kg}$, iv) were induced. Both were associated with lung microvascular permeability increases consistent with capillary endothelial injury. Eight-hour infusions of $\left[2-{ }^{13} \mathrm{C}\right]$ acetate were given. After sacrifice, bronchoalveolar washings and lung tissue were obtained and $\left[2-{ }^{13} \mathrm{C}\right]$ incorporation into lavage and lung DPPC was measured by gas chromatography mass spectroscopy. Endotoxin-treated animals had a $21.5 \%$ reduction in label incorporation into DPPC $[1.215 \pm 0.145$ APE $(\%)$ sham versus 0.954 \pm 0.144 APE (\%) experimental, $P>0.05]$ and bacteremic animals had a $56.9 \%$ diminution of $\left[2-{ }^{13} \mathrm{C}\right]$ acetate incorporation $[1.215 \pm 0.145 \mathrm{APE}(\%)$ sham versus 0.524 \pm 0.56 APE (\%) experimental, $P<0.05$ ]. Bacteremiainduced dysfunction of alveolar type II epithelial cells manifested as diminished alveolar surfactant phospholipid production may be a contributing factor to sepsisinduced respiratory failure. (๑) 1989 Academic Press, Inc.

\footnotetext{
${ }^{1}$ Presented at the Annual Meeting of the Association for Academic Surgery, Salt Lake City, UT, November 16-19, 1988.

${ }^{2}$ Supported in part by The National Institutes of Health, Grant HL38141.
}

\section{INTRODUCTION}

Acute respiratory failure associated with sepsis is one of the primary causes of morbidity and mortality in a surgical critical care environment. Features of sepsis-induced acute lung injury include alveolar capillary endothelial injury, increased microvascular permeability, interstitial edema formation [1-4], intraalveolar hemorrhage and fibrin deposition, influx of inflammatory cells (particularly neutrophils) [4,5], complement activation $[6,7]$, and alterations in the pulmonary arterial and capillary beds $[8,9]$. Both endotoxemia and bacteremia generate acute lung injury experimentally and both are associated with acute respiratory failure and ARDS clinically.

The role of surfactant in ARDS-like acute lung injury is not entirely clear but has come under increasing scrutiny in clinical and experimental lung injury [10-13]. In particular, it was recently noted that ARDS-like oxygen radical-mediated lung injury is accompanied by alterations in alveolar surfactant properties [14]. It has been known for some time that alveolar type II cells undergo proliferation and presumably increased surfactant production during the process of repair after lung injury [4, 15]. A variety of quantitative and qualitative surfactant deficiencies have been reported with acquired acute respiratory failure [10-13]. These observations collectively suggest that loss of functional surfactant may contribute to ARDS-like acute lung injury. These deficiencies may result from diminished synthesis, diminished release, increased catabolism, or alterations in composition. The purpose of this investigation was to evaluate the processes of surfactant synthesis and alveolar distribution in response to experimental endotoxemia and bacteremia. Importantly, the methodology employed is applicable to humans in that a stable isotope precursor $\left(\left[2{ }^{13} \mathrm{C}\right]\right.$ acetate $)$ rather than a radioisotope was given and rates of incorporation into small samples of alveolar lavage dipalmitoylphosphatidylcholine (DPPC) were measured.

\section{METHODS}

\section{Animal Model}

Male $350 \mathrm{~g}$ Sprague-Dawley rats were prepared by placing sterile Silastic central venous catheters $(0.020 \mathrm{~mm}$ 
internal diameter); (Dow Corning, Midland, MI) via the jugular vein and tunneling subcutaneously, exiting in the dorsal cervical region. Ketamine anesthesia $(100 \mathrm{mg} / \mathrm{kg}$, ip) was used and all protocols were approved by the University of Michigan Review Committee for the Use of Laboratory Animals. After overnight recovery, the rats were placed in individual metabolic cages and randomly assigned to the following groups: (Controls) a $1-\mathrm{ml}$ iv bolus of physiologic saline was given $(n=9)$; (Escherichia coli) a sublethal $1-\mathrm{ml}$ intravenous bolus of live bacteria $\left(1 \times 10^{8}\right.$ organisms $/ \mathrm{ml})$ was given $(n=6)$; or (Endotoxin) a $1 \mathrm{ml}$ iv bolus of endotoxin, also a sublethal dose, was given (Difco,; LPS B, 026:B6; $10 \mathrm{mg} / \mathrm{kg})(n=5)$.

\section{E. Coli Preparation}

One milliliter of saline containing $10^{8}$ live E. coli (Dunwald strain B15:0125) was given as an intravenous bolus at Time 0 . The number of organisms was routinely determined by optical density and colony counts, and their viability assured by growth from blood cultures taken from the study animals [16].

\section{Animal Protocol}

Following placement into one of the three groups, all animals received identical intravenous infusions of [2${ }^{13} \mathrm{C}$ ]acetate. Heparin flushes were not used in order to avoid heparin-induced changes in plasma fatty acid levels. $\left[2{ }^{13} \mathrm{C}\right]$ acetate (Tracer Technology, Newton, MA) was administered intravenously to the unrestrained awake rats using a Harvard-type continuous infusion pump. Infusions were of physiologic saline with a concentration of approximately $6 \mu$ mole of acetate per milliliter for a dose adjusted to $10 \mu \mathrm{mole} / \mathrm{kg} / \mathrm{min}$. Infusions did not exceed 2 $\mathrm{ml}$ per hour and were $8 \mathrm{hr}$ in duration. At the conclusion of acetate infusion, sacrifice was immediate using an intravenous ketamine bolus $(100 \mathrm{mg} / \mathrm{kg})$. Median sternotomy was performed with extension into the neck. The trachea was isolated, ligated proximally, and cannulated with an 18-gauge polyethylene catheter. Alveolar wash with $11 \mathrm{ml}$ of saline was performed. We found that this volume visibly filled and distended all lobes of both lungs. This alveolar wash was aspirated and subsequently analyzed for phospholipid incorporation of $\left[{ }^{13} \mathrm{C}\right]$ acetate. After the alveolar wash, the right lung was excised, dividing the pulmonary hilum centrally. 'The pulmonary artery was cannulated using an 18-gauge polyethylene catheter and $2.5 \times$ magnification. Residual blood was eliminated from the specimen by two intravascular washes with $15 \mathrm{cc}$ of sterile saline. Approximately $1 \mathrm{~g}$ of wet washed lung parenchyma was used for analysis of $\left[{ }^{13} \mathrm{C}\right]$ phospholipid content.

\section{Alveolar Wash Analysis}

Usually 8-9 $\mathrm{ml}$ of saline was recovered from the rat lungs. Of this, a 1-ml aliquot was added to $4 \mathrm{ml}$ of chloroform:methanol (2:1) in a Teflon-lined screw-capped test tube and shaken vigorously for $1 \mathrm{~min}$. The lower layer was transferred to a new tube and dried under $\mathrm{N}_{2}$. The dried sample was redissolved in chloroform:methanol (2: 1) for administration to TLC plates. Chloroform:methanol:2.5 $\mathrm{N} \mathrm{NH}_{3} \mathrm{OH}$ (65:25:4) was used as solvent for thinlayer chromatography. Sample as well as phospholipid standard was administered to the plate. The plate was developed in an iodine chamber, after which the phospholipid band was scraped into a test tube and $1 \mathrm{ml} \mathrm{BF}{ }_{3}$ methanol was added and the tubes sealed tightly. The sample was incubated at $80^{\circ} \mathrm{C}$ for $15 \mathrm{~min}$, and then $1 \mathrm{ml}$ hexane was added and shaken for $1 \mathrm{~min}$. The upper layer was transferred to new clean tubes, dried under $\mathrm{N}_{2}$, and then redissolved in hexane for gas chromatography mass spectrometry analysis. Palmitate enrichment was determined as described below.

\section{Lung Tissue Analysis}

Tissue (about $1 \mathrm{~g}$ ) was added to $19 \mathrm{ml}$ chloroform: methanol (2:1) and homogenized using a Brinkmann (Fisher, Fairlawn, NJ) tissue homogenizer. The sample was centrifuged, and $3.8 \mathrm{ml} 0.88 \% \mathrm{KCl}$ was added. The upper phase was discarded, and $0.2 \mathrm{ml}$ of the lower phase dried. The sample was then reconstituted in $50 \mu \mathrm{l}$ chloroform:methanol (2:1) and spotted on the TLC plate. Sphingomyelin, phosphatidylcholine, $\mathrm{P}$-ethanolamine, $\mathrm{P}$ inositol, and $\mathrm{P}$-serine derivatives for GCMS analysis were made as described for lavage, except for sphingomyelin. Sphingomyelin was extracted from the silica gel, then 1 $\mathrm{ml}$ of $2 \% \mathrm{H}_{2} \mathrm{SO}_{4}$ in anhydrous methanol was added, the tube sealed and heated at $90^{\circ} \mathrm{C}$ for $16 \mathrm{hr}$. One milliliter hexane and $0.1 \mathrm{ml} \mathrm{H}_{2} \mathrm{O}$ were added and the tube was shaken vigorously. The hexane layer (upper phase) was dried down, then taken back up in hexane for analysis. Palmitate enrichment was determined on the methyl ester of palmitate using a Hewlett-Packard 5985B gas chromatograph mass spectrometer using electron impact ionization and selective ion monitoring of molecular ions at $m / e 271$ and $m / e 272$, as described in detail previously [17]. Each sample was run in duplicate to ensure accuracy; the average enrichment for each sample was used for statistical analysis.

\section{Lung Microvascular Permeability Assessment}

In separate animals identically prepared, an intravenous bolus [ $1 \mathrm{ml}$ of ${ }^{125} \mathrm{I}$-bovine serum albumin (BSA) $(800,000 \mathrm{cpm})]$ was given $3 \mathrm{hr}$ prior to sacrifice to assess microvascular permeability changes. Immediately following infusion, the rats were sedated with ketamine hydrochloride $(50 \mathrm{mg} / \mathrm{kg}$, ip). Laparotomy was performed, $1 \mathrm{ml}$ of blood was aspirated from the inferior vena cava (IVC). The IVC was transected to exsanguinate the animal. The heart and lungs were removed en bloc and $10 \mathrm{ml}$ of sterile saline was infused into the right ventricle to wash residual blood and ${ }^{125}$ I-BSA from the pulmonary vascular bed. Done rapidly, a spontaneous heart beat persisted and the lung parenchyma developed a typical white blanched appearance when bloodless. The whole lungs were counted 
in a gamma scintillation counter with the $1 \mathrm{ml}$ blood sample. The ratio of lung to blood counts was taken as a measure of microvascular permeability and has been shown to be a reliable, quantifiable marker of lung injury in this as well as other lung injury models [5, 7]. This aspect of permeability assessment is described in detail in several recent publications $[5,7,18]$.

\section{Histology}

For histological study, additional rats were prepared identically without ${ }^{125}$ I-BSA injections. At sacrifice the lungs were inflated via the trachea with $4 \%$ glutaraldehyde in cacodylate buffer. After fixation, biopsies were taken from each lobe of the lung and embedded in epon. For light microscopy studies, $1-\mu \mathrm{m}$ sections were taken from the plastic blocks and stained with toluidine blue. For electron microscopy, ultrathin sections were cut and processed for ultrastructural analysis using a Philips 401 transmission electron microscope (Philips Co., Amsterdam, The Netherlands).

\section{RESULTS}

Microvascular permeability data are presented in Table 1. The data are expressed as the ratio of lung counts compared to a reference of counts per $1 \mathrm{ml}$ of blood. This technique eliminates the variability inherent in injecting small volumes of a tracer and provides data which are intuitively interpretable. For example, a ratio of $0.20 \mathrm{in}$ dicates that $20 \%$ of the intravascular ${ }^{125}$ I-BSA label has been sequestered in the extravascular compartment during the experimental period.

\section{Evidence for Increased Microvascular Permeability and Endothelial Cell Injury (Table 1)}

One hour after induction of bacteremia or endotoxemia microvascular permeability is not statistically different. At later time points, 3 and $6 \mathrm{hr}$, the permeability index is significantly elevated, consistent with increased capillary permeability and the extravascular accumulation of the ${ }^{125}$ I-BSA. In addition, representative photomicrographs of normal and injured (endotoxin-treated) lung are shown at the 3-hr time point in Figs. 1a, 1b, and 1c. The histological features are not different for bacteremia and endotoxemia. These features include interstitial edema formation, alveolar capillary endothelial cell injury, neutrophil infiltration, and intraalveolar hemorrhage.

\section{Evidence for Diminished Precursor Incorporation into Bronchoalveolar Lavage and Lung Tissue Phosphatidylcholine (Table 2)}

All data are expressed as Atoms Percent Excess (APE) (\%). This represents the fraction of ${ }^{13} \mathrm{C}$ in the DPPC samples minus the naturally occurring background level of ${ }^{13} \mathrm{C}$ and is expressed as a percentage. The data therefore
TABLE 1

\section{Microvascular Permeability Index Changes Related to Time of Bacteremia and Endotoxemia ${ }^{a}$}

\begin{tabular}{ccll}
\hline $\begin{array}{c}\text { Time } \\
\text { after injection }\end{array}$ & Sham & Endotoxemia & Bacteremia \\
\hline $1 \mathrm{hr}$ & $0.146 \pm 0.03$ & $0.258 \pm 0.09$ & $0.240 \pm 0.06$ \\
$3 \mathrm{hr}$ & $0.153 \pm 0.02$ & $0.394 \pm 0.03^{*}$ & $0.397 \pm 0.05^{*}$ \\
$6 \mathrm{hr}$ & $0.247 \pm 0.02$ & $0.440 \pm 0.06^{*}$ & $0.475 \pm 0.15$ \\
\hline
\end{tabular}

${ }^{a}$ Permeability Index calculated as lung/blood cpm (see text).

${ }^{*} P<0.05$, Student's $t$ test compared to appropriate sham; (data expressed as means \pm SEM).

reflect the degree of sample enrichment attributable to infusion of the $\left[2-{ }^{13} \mathrm{C}\right]$ acetate precursor followed by synthesis into dipalmitolyphosphatidylcholine. The APE of lavage samples is taken then to reflect the rate of DPPC elaboration into alveolar surfactant. A detailed discussion of this calculation is recently provided $[17,19]$. The assumption is made here as it has been by others, that alveolar lavage DPPC is derived principally from the contribution of alveolar surfactant $[13,20]$.

Bronchoalveolar lavage DPPC ${ }^{13} \mathrm{C}$ enrichment is significantly diminished $(-56.9 \%)$ from baseline in rats with $E$. coli bacteremia $(1.215 \pm 0.145 \%$ for controls versus $0.524 \pm 0.056 \%$ for $E$. coli, $P=0.003$ ). A similar assessment in rats with endotoxemia shows a diminished rate of precursor ${ }^{13} \mathrm{C}$ incorporation $(-21.5 \%)$ that does not achieve statistical significance $(1.215 \pm .145 \%$ for controls versus $0.954 \pm .144$ for endotoxin, $P=0.35$ ). Hence, the rate of alveolar surfactant DPPC production appears significantly diminished with $E$. coli bacteremia.

Lung tissue DPPC ${ }^{13} \mathrm{C}$ enrichment is diminished in a parallel manner. Bacteremic animals have a significant reduction $(-62.5 \%)$ from baseline of ${ }^{13} \mathrm{C}$ incorporation into DPPC (1.116 $\pm 0.217 \%$ for controls versus 0.418 $\pm 0.049 \%$ for $E$. coli-treated animals, $P=0.019$ ). Rats with endotoxemia again show a reduction $(-38.7 \%)$ that does not achieve statistical significance $(1.116 \pm 0.717 \%$ for controls versus $0.684 \pm 0.221$ for endotoxin, $P=0.293$ ).

\section{DISCUSSION}

Based upon the hypothesis that biochemical change in surfactant phospholipid synthesis is likely to precede the gross physiologic alterations seen with clinical respiratory failure, we have developed a technique designed to evaluate in vivo lung phospholipid synthesis. The utility of this technique includes human use, and possibly clinical use as a prognostic test for patients with early or impending respiratory distress. Unlike previous techniques using radioactive labels, this technique uses a stable isotope tracer $\left(\left[2 \cdot{ }^{13} \mathrm{C}\right]\right.$ acetate $)$ and therefore presents no health risk. Additional advantages are that a very small phospholipid sample is sufficient so that alveolar wash 

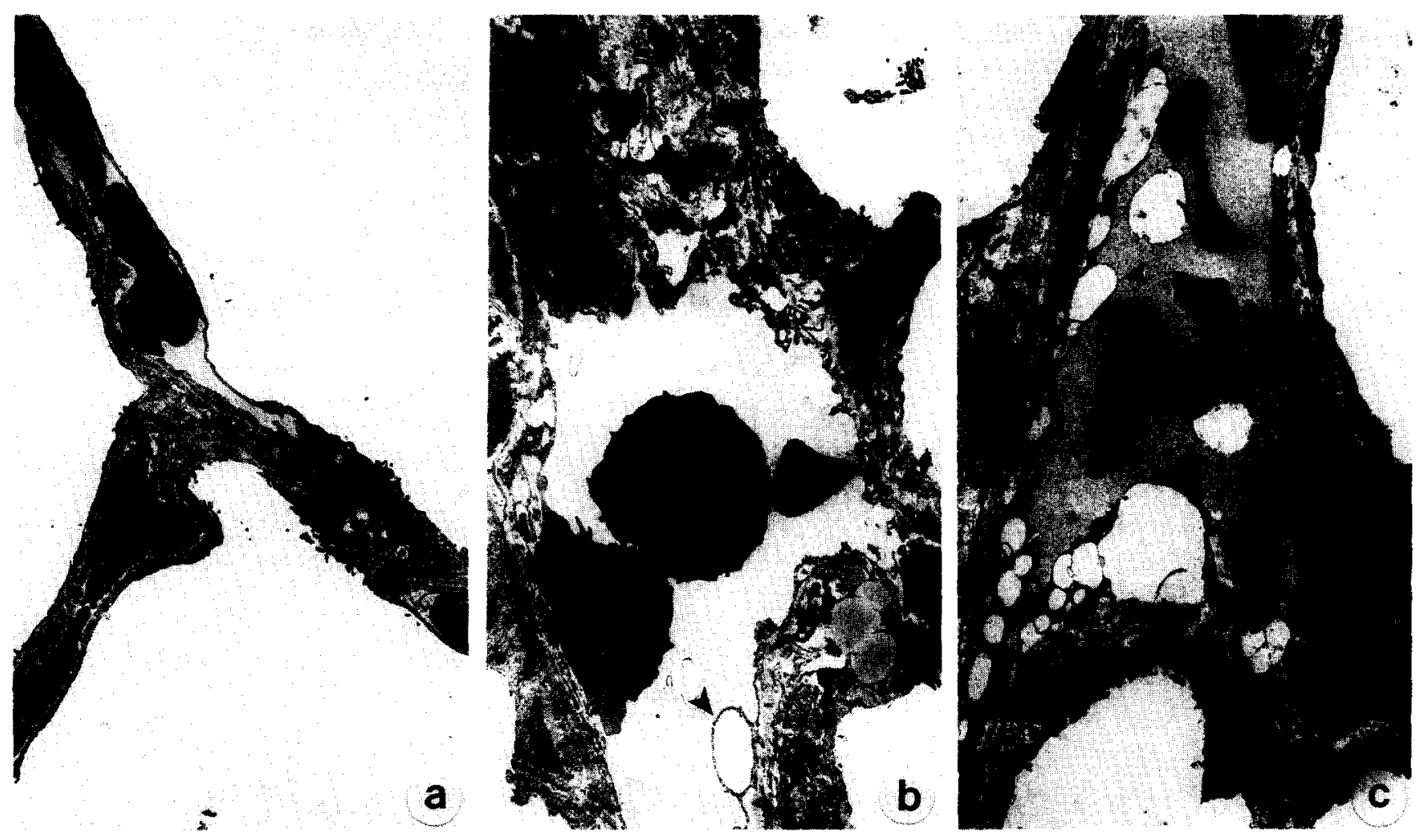

FIG. 1. Normal lung from sham rats is illustrated in panel a. Panels $\mathrm{b}$ and $\mathrm{c}$ from bacteremic and endotoxin-treated rat lung, respectively, illustrate the features of interstitial edema $(\leftarrow \rightarrow)$, capillary endothelial cell injury with blebbing $(\leftarrow)$, and neutrophil sequestration $(b)$. These are characteristic findings in the lungs of rats with either bacteremia or endotoxemia. $(3150 \mathrm{X})$

samples are practical. The use of stable isotopes makes this technique safe and specific. In addition, ${ }^{13} \mathrm{C}$ enrichment of each fatty acid of each lipid can be individually quantitated so that investigation can reasonably be extended beyond phosphatidylcholine. For example, the synthetic rate of phosphatidylglycerol, another lipid of interest in the pathogenesis of ARDS [4, 10], can also be estimated.

In these particular experiments acute lung injury was induced separately by intravenous endotoxin injection and by live $E$. coli injection. Many of the systemic consequences of these insults are known. In particular acute lung injury with alveolar capillary endothelial injury and increased microvascular permeability has been characterized [1-4]. These proved to be important features of these sublethal sepsis models as well (Table 1 and Fig. 1). Additionally this study examines the response of the lung to these injuries with regard to the phospholipid component of the surfactant system.

Interest in the surfactant system in acute respiratory failure was initially derived from experience with premature infants in whom a quantitative deficiency of surfactant was clearly the primary etiology $[13,21,22]$. Adult respiratory failure and ARDS-like acute lung injury are multifactoral. Both quantitative and qualitative surfactant defects are recently described in ARDS-associated respiratory failure [10-13]. The nature of these defects appears to be specific for particular experimental models. The clinical implications of these observations are not yet clear. This study illustrates that the incorporation of a $\left[2-{ }^{13} \mathrm{C}\right]$ acetate precursor into alveolar lavage dipalmitoylphosphatidylcholine (DPPC) is diminished significantly in rats with $E$. coli bacteremia.

\section{TABLE 2}

The Effect of Endotoxemia and E. Coli Bacteremia on ${ }^{13} \mathrm{C}$ Enrichment of DPPC in Lung Tissue and Bronchoalveolar Lavage

\begin{tabular}{|c|c|c|c|c|}
\hline \multirow[b]{2}{*}{ Intervention } & \multicolumn{2}{|c|}{ Lavage } & \multicolumn{2}{|c|}{ Lung tissue } \\
\hline & $\begin{array}{c}{ }^{13} \mathrm{C} \\
\text { enrichment } \\
\text { APE }(\%)^{a}\end{array}$ & $\begin{array}{c}\% \\
\text { change }\end{array}$ & $\begin{array}{c}{ }^{13} \mathrm{C} \\
\text { enrichment } \\
\text { APE }(\%)\end{array}$ & $\begin{array}{c}\% \\
\text { change }\end{array}$ \\
\hline $\begin{array}{l}\text { Acetate alone } \\
\text { (sham) }\end{array}$ & $1.215 \pm 0.145$ & - & $1.116 \pm 0.217$ & - \\
\hline $\begin{array}{l}\text { Acetate } \\
\quad+\text { E. coli }\end{array}$ & $0.524 \pm 0.056^{*}$ & $-56.9 \%$ & $0.418 \pm 0.49^{*}$ & $-62.5 \%$ \\
\hline $\begin{array}{l}\text { Acetate } \\
\quad+\text { endotoxin }\end{array}$ & $0.954 \pm 0.144$ & $-21.5 \%$ & $0.684 \pm 0.221$ & $-38.7 \%$ \\
\hline
\end{tabular}

${ }^{a}{ }^{13} \mathrm{C}$ enrichment expressed as atoms percent excess (APE, \%) (see text)

* $P<0.05$ compared to appropriate Sham, Student's t-test 
Surfactant itself is a complex moiety composed of protein, carbohydrate, and phospholipid components. The phospholipid component is not independently sufficient, but contributes substantially to its physiologic role as a surface-active substance coating alveoli which reduces surface tension and maintains alveolar inflation. Of the surfactant phospholipids produced by alveolar type II cells, DPPC is the most abundant, representing approximately $50 \%$ of the total [20]. Indeed, therapeutic trials of artificial surfactants have focused upon strategies for replacing alveolar DPPC [13]. For this reason DPPC was selected as the index alveolar phospholipid in these experiments. As noted, other phospholipids can be assessed with this methodology and may well yield important findings.

A potential criticism of the approach proposed is that the bronchoalveolar lavage specimens obtained might not reflect the alveolar surfactant pool accurately. Although this could be true, a number of previous investigators have validated the general concept of bronchoalveolar lavage evaluation for surfactant sampling $[10,20]$. King and Clements pooled data from different laboratories and found that the phospholipid composition of rat alveolar epithelial type II cells, rat type II cell lamellar bodies, and rat pulmonary surfactants purified from lavage fluid are similar [20]. In this series of experiments, we have obtained distributions of phospholipid species in rat bronchoalveolar lavage specimens similar to those reported by King and Clements [20]. Additional support for the assumption that lavage phospholipids reflect type II cell phospholipid composition is provided by the data for lung tissue DPPC rates of ${ }^{13} \mathrm{C}$ enrichment. The parallel changes in the lung tissue DPPC and lavage enrichment rates are clear in Table 2. This suggests that cellular pools as well as extracellular phospholipid pools (including alveolar surfactant) are affected similarly by the injury. Although the lung tissue phospholipid pool does include cell populations other than the type II cells, the similar response to endotoxemia and bacteremia is consistent with the hypothesis that type II cell production of surfactant phospholipid is diminished by these injuries. Finally, it should be emphasized that one goal of the methodology developed was to provide a simple and potentially useful clinical analysis. Clearly a benign approach such as obtaining bronchoalveolar lavage is required for patient use. We have found that reproducible alterations in the ${ }^{13} \mathrm{C}$ enrichment in lavage phospholipids occur with experimental lung injuries associated with surfactant abnormalities. These injuries include acute pancreatitis [19], exposure to hyperbaric oxygen (unpublished data), and here, bacteremia and endotoxemia. These data suggest potential clinical utility using lavage phospholipid specimens. More recently, we have used this approach in a small number of human patients and ${ }^{13} \mathrm{C}$ enrichment of lavage specimens is demonstrable. In summary, we have made the assumption, as have others, that a relationship exists between lavage and alveolar surfactant phospholipid composition.
Given the inherent limits imposed by this assumption, the data provided do suggest that the method of sampling proposed is practical, and bronchoalveolar lavage DPPC enrichment does reflect a variety of acute lung injuries for which surfactant abnormalities are suspected.

We conclude that rats with $E$. coli bacteremia have significantly reduced synthesis of the DPPC component of alveolar surfactant as reflected in bronchoalveolar lavage samples and assessed by $\left[2-{ }^{13} \mathrm{C}\right]$ acetate incorporation. Rats with endotoxemia have similarly lower rates of ${ }^{13} \mathrm{C}$ incorporation but the changes in these experiments do not achieve statistical significance. These data suggest that sepsis-induced acute lung injury and respiratory failure may be associated with a failure of alveolar type II cell phospholipid synthesis and a resultant deficiency of functional surfactant. The stable isotope analytical technique described for lavage DPPC evaluation by GCMS is potentially applicable to human clinical studies.

\section{REFERENCES}

1. Brigham, K. L., and Meyrick, B. Endotoxin and lung injury. Amer. Rev. Respir. Dis. 133: 913, 1986.

2. Newman, J. H. Sepsis and pulmonary edema. Clin. Chest Med. 6(3): 371, 1985.

3. Lium, B. Adult Respiratory Distress Syndrome (ARDS). Incidence, clinical findings, pathomorphology and pathogenesis. A review. Nord. Vet. Med. 35(1): 38, 1983.

4. Rinaldo, J. E., and Rogers, R. M. Adult respiratory-distress syndrome: Changing concepts of lung injury and repair. New Eng. J. Med. 306(15): 900, 1982.

5. Guice, K. S., Oldham, K. T., Johnson, K. J., Morganroth, M., and Ward, P. A. Pancreatitis-induced acute lung injury: An ARDS model. Ann. Surg. 208: 71, 1988.

6. Till, G. O., Beauchamp, C., Menapace, D., Tourtellotte, W., Kunkel, R., Johnson, K. J., and Ward, P. A. Oxygen radical dependent lung damage following thermal injury of rat skin. J. Trauma 23(4): 267, 1983.

7. Till, G. O., Johnson, K. J., Kunkel, R., et al. Intravascular activation of complement and acute lung injury: Dependency on neutrophils and toxic oxygen metabolites. J. Clin. Invest. 69: 1126, 1982.

8. Messmer, K., and Hammersen, F. Microcirculation and Inflammation: Vessel Wall-Inflammatory Cells-Mediator Interaction. New York: Karger, 1987.

9. Cooper, J. D., McDonald, J. W. D., Ali, M., et al. Prostaglandin production associated with the pulmonary vascular response to complement activation. Surgery 88: 215, 1980.

10. Hallman, M., Spragg, R., Harrell, J. H., Moser, K. M., and Gluck, L. Evidence of lung surfactant abnormality in respiratory failure. J. Clin. Invest. 70: 673-683, 1982.

11. Kikkawa, Y., and Smith, F. Biology of disease: Cellular and biochemical aspects of pulmonary surfactant in health and disease. Lab. Invest. 49(2): 122, 1983.

12. Smith, F. B. Role of the pulmonary surfactant system in lung disease of adults. N.Y. St. J. Med., 852, 1983.

13. Notter, R. H. Biophysical behavior of lung surfactant: Implications for respiratory physiology and pathophysiology. Semin Perinatol 12(3): 180, 1988.

14. Saugstad, O. D., Hallman, M., Abraham, J. L., Epstein, B., Cochrane, C., and Gluck, L. Hypoxanthine and oxygen indured lung 
injury: A possible basic mechanism of tissue damage? Pediatr. Res. 18(6): 501, 1984.

15. Kawanami, O., Ferrans, V. J., and Crystal, R. G. Structure of alveolar epithelial cells in patients with fibrotic lung disorders. $L a b$. Invest. 46: 39, 1982.

16. Benner, J. W., Polley, T. Z., Strodel, W. E., Drongowski, R., Weintraub, W. H., Wesley, J. R., and Coran, A. G. Fluid resuscitation in live Escherichia coli shock in puppies. J. Pediatr. Surg. 15(4): $527,1980$.

17. Wolfe, R. R. Tracers in Metabolic Research-Radioisotope and Stable Isotope/Mass Spectrometry Methods, A. R. Liss: New York, 1984.

18. Johnson, K. J., Fantone, J. C., Kaplan, J., and Ward P. A. In vivo damage of rat lungs by oxygen metabolites. J. Clin. Invest. 67: $983,1981$.
19. Guice, K. S., Oldham, K. T., Wolfe, R. R., and Simon, R. H. Lung injury in acute pancreatitis: Primary inhibition of pulmonary phospholipid synthesis. Amer. I. Surg. 153: 54, 1987.

20. King, R. J., and Clements, J. A. Lipid synthesis and surfactant turnover in the lung. In A. P. Fishman and A. B. Fisher, Ed.) The Respiratory System, Baltimore: Williams \& Wilkens 1985, pp. 309336.

21. Brown, B. J., Gabert, H. A., and Stenchever, M. A. Respiratory distress syndrome: Surfactant biochemistry, and acceleration of fetal lung maturity: A Review. Obstet. Gynecol. Surg. 30(20): 71, 1975.

22. Notter, R. H., and Finkelstein, J. N. Pulmonary surfactant: An interdisciplinary approach. J. Appl. Physiol. Respir. Environ. Ex ercise Physiol. 57(6): 1613, 1984. 